\title{
Floral gradient in flowering tobacco in relation to free amino acids
}

\author{
CHEN YONGNING, WENAN LI \\ Shanghai Institute of Plant Physiology, Academia Sinica. \\ 300 Fenglin Road, Shanghai 200032, China
}

\begin{abstract}
By employing TCLs (thin cell layers) culture, the floral gradient in flowering tobacco of different developmental stages was confirmed. The TCLs from early flowering tobacco regenerated more floral buds than those from the tobacco plants in full blooming or fruiting stages. Analysis of free amino acid levels revealed the acropetal gradient of Pro in flowering tobacco stem. L-Pro, L-Trp, D,L-Met and L-Arg were respectively added into the culture medium for testing their influence on floral bud formation from tobacco pedicel segments. Only L-Trp evidently enhanced the floral bud neoformation.
\end{abstract}

Key words: tobacco, floral bud differentiation, floral gradient, free amino acid, thin cell layers culture, $L-\operatorname{Tr}$.

\section{INTRODUCTION}

In 1961, Chouard and Aghion[1] first discovered the floral gradient in flowering tobacco plants and this phenomenon was also observed in Torenia fournieri, Cichorium intybus, Passiflora suberosa and Hieracium floribundum[2]. It is hypothesized that this gradient reflected a gradient of floral substances. Based on this view point, some substances related to floral gradient were examined, e.g. DNA, phytohormones and polyamine[3-7]. Among them, phytohormones and polyamine were known to be involved in floral bud neoformation in vitro, such as spermidine could enhance

1. This project was supported by the Major Project Foundation of Academia Sinica and the Director Fund of Shanghai Institute of Plant Physiology, Academia Sinica.

Abbreviations used: TCLs-Thin Cell Layers, IAA-indole-3-acetic acid, IBAindolebutyric acid, 6-BA-6-benzyl aminopurine, Pro-proline, Trp-tryptophan, Arg-arginine, Met-methionine, Asp-aspartic acid, Glu-glutamic acid, Gly-glycine, Ala-alanine, Val-valine, Ile-isoleucine, Leu-leucine, Tyr-tyrosine, Phe-Phenyl-alanine, His-histidine, Lys-lysine, Serserine, Thr-threonine, Cys-cysteine, Asn-asparagine, Gln-glutamine. 
Florl gradient and free amino acids in flowering tobacco

the floral bud differentiation in tobacco tissue culture[S]. In 1969, Vallee et al.[9] found the Pro acropetal gradient in flowering tobacco stem. However, there have been no further reports about Pro in tobacco floral bud differentiation. In addition, study on the influence of exogenous amino acids on floral bud differentiation has so far been very limited[10], although amino acids are essential in plant development. Therefore, in the present work, we tested the relation between floral gradient and free amino acids, and the effect of some exogenous amino acids on florM bud neoformation in vitro.

\section{MATERIALS AND METHODS}

\section{Plant materials}

Flowering plants of day-neutral tobacco (Nicotiana tabacum L. cv. Ge Xing 1) grown in an artificially illuminated phytotron were used as the experimental material. The explants: 1 . TCLs (about 5-8 mm long, 1-2 mm wide) composed of epidermis and several layers of parenchymatous cells [11] stripped from stem, floral branches and pedicels of tobacco plants in early flowering (only the first flower opened), full blooming or fruiting stages; 2 . flower pedicel segments (about 1-2 mm in length); 3. leaf pieces (about $5 \mathrm{~mm}$ long, $5 \mathrm{~mm}$ wide) from vegetative tobacco plants. All the explants were sterilized with routine methods.

\section{Culture methods}

The basic medium was composed of inorganic salts and organic elements of modified Murashige and Skoog's medium (MS medium)[12], inositol $100 \mathrm{mg} / \mathrm{L}$, sucrose $30 \mathrm{~g} / \mathrm{L}$ and agar 5.2-6 g/L. According to the requirements of the experiments, phytohormones, plant growth regulators or amino acids were respectively added into the basic medium (for details, see Results). Before autoclaved, the medium was adjusted to $\mathrm{pH} 5.8$ with $1 \mathrm{~N} \mathrm{NaOH}$.

As a rule, 8-10 explants were inoculated for one petri dish $(6 \mathrm{~cm}$ in diameter) and incubated in a culture box at $22^{\circ} \mathrm{C}$ (night) to $25^{\circ} \mathrm{C}$ (day) under $15 \mathrm{~h}$. illumination (about $4000 \mathrm{Lux}$ ) produced by cool-white fluorescence [13]. The results were recorded after culturing for about 4 weeks:

\section{Extraction and determination of free amino acids}

Free amino acids in fresh samples were extracted with $80 \%$ alcohol according to Wang and Fang(14). The contents of free amino acids were determined with high performance amino acid analyzer, the system 6300 series, Beckman. The standard sample of Trp was freshly made up for every determination.

\section{RESULTS}

\section{Floral gradient in different developmental stages}

The floral gradients in different developmental stages had been determined by the method of TCLs culture. The results were shown in Tab 1.

The results in Tab 1 showed that the floral gradients were obvious in 3 different developmental stages (see the percentages in Tab 1: F-TCLs/T-TCLs). The TCLs with the competence for floral bud formation were mainly taken from the apical region, i. e. from stem region I to floral pedicels. However, the TCLs from the early flowering plants formed more floral buds than those from other 2 stages. The floral buds formed from pedicel TCLs or fruit stalk TCLs were leafless (Fig 1), but 
most of the floral buds formed from floral branches and stem region I TCLs were, in fact, floral shoots with one or more leaves. In addition, fewer vegetative buds were formed from pedicel and fruit stalk TCLs (see V/TCLs in Tab 1).

\section{Levels of free amino acids in different regions of flowering tobacco}

The assaying results of free amino acids listed in Tab 2 revealed that the contents of free amino acids in apical parts of flowering tobacco plants were higher than those in basal parts, and the acropetal gradient of Pro in flowering tobacco stem could obviously be visible.

The Pro level reached about $2 \mathrm{mg} / \mathrm{g}$ fresh tissue in the apical zone of stem or flower zone. However, the contents of the other free amino acids (Val, Ile, Tyr, Arg and so on) were extremely low, even not detectable.

Tab 1. De novo floral bud differentiation from TCLs as influenced by the origins of explants*

\begin{tabular}{|c|c|c|c|c|c|c|}
\hline \multicolumn{2}{|c|}{ Origins of TCLs } & $\begin{array}{c}\text { Total } \\
\text { of TCLs }\end{array}$ & $\begin{array}{c}\text { F-TCLs } \\
(\%) \\
\text { T-TCLs }\end{array}$ & F/F-TCLs & $\mathrm{V} / \mathrm{TCLs}$ & D-TCLs \\
\hline & Pedicel & 30 & 100 & 10.2 & 0.6 & 0 \\
\hline Early & Floral branch & 45 & 89 & 14.1 & 9.4 & 0 \\
\hline flowering & stem I & 54 & 0 & 0 & 13.9 & 0 \\
\hline stage & II & 43 & 0 & 0 & 5.4 & 0 \\
\hline & III & 31 & 0 & 0 & 5.4 & 10 \\
\hline & IV & 40 & 0 & 0 & 1.6 & 33 \\
\hline & Pedicel & 74 & 77 & 2.5 & 0 & 0 \\
\hline Full & Florsl branch & 77 & 22 & 7.9 & 1.7 & 0 \\
\hline blooming & Stem I & 61 & 10 & 3.5 & 0.5 & 0 \\
\hline stage & II & 47 & 0 & 0 & 0.4 & 1 \\
\hline & III & 40 & 0 & 0 & 0.3 & 13 \\
\hline & IV & 48 & 0 & 0 & 2.0 & 43 \\
\hline & Fruit stalk & 68 & 99 & 3.5 & 0.4 & 0 \\
\hline Fruiting & Fruit branch & 70 & 93 & 6.5 & 0.6 & 0 \\
\hline stage & Stem I & 80 & 10 & 3 & 3.5 & 3 \\
\hline & II & 70 & 0 & 0 & 2.7 & 7 \\
\hline & III & 60 & 0 & 0 & 2.7 & 33 \\
\hline & IV & 72 & 0 & 0 & 3.2 & 44 \\
\hline
\end{tabular}

* All TCLs were cultured on the basic medium + IBA $2 \mathrm{mg} / \mathrm{L}+6$-BA $0.2 \mathrm{mg} / \mathrm{L}$.

F- TCLs: TCLs with regenerated flower buds.

T- TCLs: Total of TCLs cultured.

D- TCLs: TCLs died in culture.

F /F- TCLs: Average of regenerated flower buds on one F-TCLs.

V/TCLs: Average of regenerated vegetative buds on one TCLs (TCLs $=\mathrm{T}-\mathrm{TCL} \mathrm{s}-\mathrm{D}-\mathrm{TCL} \mathrm{s}$ ).

Stem I - IV: representing the different regions of tobacco stem from apex to base at an interval of about 8 nodes each. 
Floral gradient and free amino acids in flowering tobacco

Tab 2. The contents of 15 free amino acids in different parts of flowering tobacco*

\begin{tabular}{|c|c|c|c|c|c|c|}
\hline \multirow{3}{*}{$\begin{array}{l}\text { Type } \\
\text { of } \\
\text { amino } \\
\text { acids }\end{array}$} & \multicolumn{6}{|c|}{ The contents of free amino acids ( $\mu \mathrm{g} / \mathrm{g}$ fresh weight) } \\
\hline & \multicolumn{3}{|c|}{ Flowering zone } & \multicolumn{3}{|c|}{ Stem } \\
\hline & $\begin{array}{l}\text { Fruit } \\
\text { stalk }\end{array}$ & Pedicel & $\begin{array}{l}\text { Floral } \\
\text { branch }\end{array}$ & $\begin{array}{c}\text { Apical } \\
\text { zone }\end{array}$ & $\begin{array}{c}\text { Middle } \\
\text { zone }\end{array}$ & $\begin{array}{l}\text { Basal } \\
\text { zone }\end{array}$ \\
\hline Pro & 2155 & 1616 & 2039.5 & 2146 & 1433 & 407.1 \\
\hline Trp & 128.59 & 321.88 & 80.67 & 84.40 & 81.90 & 47.38 \\
\hline Aeg & nd & $17.02^{\triangle}$ & 17.40 & 33.96 & nd & nd \\
\hline Met & 14.47 & 12.69 & 11.11 & 15.25 & 14.32 & 5.21 \\
\hline Asp & 204.01 & 135.50 & 197.80 & 134.9 & 138.8 & 107.4 \\
\hline Glu & 552.10 & 275.50 & 285.30 & 277.3 & 260.9 & 177.7 \\
\hline Gly & 17.11 & 13.78 & 22.40 & 14.30 & 14.65 & 6.09 \\
\hline Ala & 57.40 & 63.90 & 41.28 & 29.77 & 27.85 & 15.49 \\
\hline Val & nd & nd & nd & nd & nd & nd \\
\hline $\mathrm{He}$ & nd & nd & nd & nd & $9.57^{\triangle}$ & nd \\
\hline Leu & 31.76 & $20.30^{\triangle}$ & 28.88 & 36.12 & 37.79 & 19.88 \\
\hline Tyr & 22.73 & nd & nd & nd & nd & nd \\
\hline Phe & $20.80^{\triangle}$ & 32.04 & 32.19 & 27.9 & $20.80^{\triangle}$ & $12.27^{\triangle}$ \\
\hline His & 24.97 & 25.04 & 13.80 & 20.51 & 19.85 & 10.39 \\
\hline Lys & 13.99 & 20.53 & 11.91 & 21.08 & 15.67 & 17.24 \\
\hline
\end{tabular}

*Except for fruit stalk, the other samples were all taken from flowering tobacco plants with only a few flowers blossomed.

The figures were the average of the 2 determinations, the mean error was $11.73 \%$ and the standard deviation was $9.7 \%$.

nd: not detectable; $\triangle: 1$ determination, the other sample not detectable.

Ash, Ser, Thr, Gin and Cys had not been determined in the present work.

\section{Influence of exogenous amino acids on floral differentiation from pedicel segments}

According to the results in Tab 2 and the known roles of amino acids in plant metabolism, 4 amino acids (Pro, Trp, Arg and Met) were chosen to be added into the No.120 medium (the basic medium + IA A $2 \mathrm{mg} / \mathrm{L}+6$-BA $0.2 \mathrm{mg} / \mathrm{L}$ ) for testing their effects on flower bud formation. Tab 3 showed the results of this experiment.

It was evident from Tab 3 that 3 amino acids L-Pro (at 100, $1000 \mathrm{mg} / \mathrm{L}$ ), D,LMet and L-Arg (at all concentrations used) inhibited the floral bud formation and L-Pro $1 \mathrm{~g} / \mathrm{L}$ was distinctly poisonous to explants (Fig 2). But, L-Trp could obviously enhance the floral bud formation from pedicel segments. Further researches revealed that L-Trp combining with 6-BA also promoted floral bud differentiation (Fig 3-4). The frequency of the pedicel segments regenerating floral buds reached 68.6\%(48/70) on the medium (the basic medium + L-Trp $4 \mathrm{mg} / \mathrm{L}+6$-BA $2 \mathrm{mg} / \mathrm{L}$ ). However, when only L- Trp was added into the basic medium, no floral bud neofor- 
mation could be observed (Fig 3)

Tab 3. The influence of exogenous amino acids on floral bud differentiation from tobacco pedicel segments*

\begin{tabular}{|c|c|c|c|c|}
\hline Type & Concentration $(\mathrm{mg} / \mathrm{L})$ & TPS & FPS /TPS(\%) & MFBS \\
\hline CK & 0 & 125 & 72.8 & 10 \\
\hline \multirow[t]{3}{*}{ L-Pro } & 10 & 156 & 82.7 & 18 \\
\hline & 100 & 177 & 29.9 & 5 \\
\hline & 1000 & 188 & 0 & 0 \\
\hline \multirow[t]{6}{*}{ L-Arg } & 5 & 150 & 39.3 & 5 \\
\hline & 25 & 150 & 33.3 & 5 \\
\hline & 125 & 150 & 41.3 & 7 \\
\hline & 5 & 130 & 71.5 & 17 \\
\hline & 25 & 120 & 48.3 & 7 \\
\hline & 125 & 130 & 24.6 & 9 \\
\hline L-Trp*** & 16 & 200 & 96.0 & 25 \\
\hline
\end{tabular}

\section{Effect of L-Trp and L-Pro on organ differentiation from vegetative explants}

The results outlined above showed that L-Trp and lower concentration of L-Pro enhanced floral bud differentiation from the tobacco pedicel segments. Therefore, further research on the effect of L-Trp and L-Pro was carried out with explants from vegetative tobacco plants.

The stem TCLs from the region II of flowering tobacco plant (Early flowering stage, cf. Tab 1) and leaf pieces from vegetative tobacco plants were cultured on a series of media containing L-Trp + 6-BA or L-Pro + IAA + 6-BA. In all cultures, the TCLs and leaf pieces differentiated into adventitious vegetative buds, but no floral buds, and the higher concentration of L-Pro obviously inhibited the vegetative bud formation (Fig 5-6). Apparently, L-Trp or L-Pro was unable to induce floral bud formation from vegetative explants.

\section{DISCUSSION}

Plant gradient (e.g. Gradients of signals or of cellular traits) may be resulted from the changes occurring in the apical meristems, and the changes were maintained in the mature cells they produced[15]. Thus, it is possible to investigate the gradients of substances related to flowering through the floral gradient. For example, ABA has been found to be closely related to floral gradient in Torenia fournieri 
in this way[16]. The results here showed that the floral gradient in flowering tobacco plant was obvious in different stages, although the frequencies of floral bud regeneration from TCLs varied with the developmental stages. The determination of free amino acids confirmed the Pro gradient in flowering tobacco stem and showed higher contents of free amino acids (cf. Tab 2) (e.g. pro, Trp, Ala, etc.) in flowering zone and stem apical zone. But gradient of tryptobane and its quantity were not as obvious and large as gradient of prolive Kutacek reported that tobacco tissues in vitro could utilize L-Trp to synthesize IAA via indolylpyruvate pathway[17], so the enhancement of floral bud formation by L-Trp could logically be explained. The explants from tobacco pedicel, whose Trp level was the highest among the tissues analyzed in flowering tobacco, had stronger competence for floral bud formation than that from other parts of the plant. But L-Trp could not induce flower buds from vegetative explants. Hence, according to the model of multifactorial control suggested by Bernier[18], L-Trp may be just only one of the factors related to floral bud differentiation.

Pro was usually considered as non-poisonous to plants[19]. In the present work, L-Pro at low concentration (10 rag/L) had a promoting, although mild, effect on floral bud neoformation. This promotion was also reported in the work with root explants of Cichorium on floral bud differentiation in vitro[10]. However, it is very difficult to explain the poisonous effect of L-Pro at high concentration $(1 \mathrm{~g} / \mathrm{L})$ in vitro, considering the large accumulation of Pro in vivo (see Tab 2) and the high concentration of L-Pro (100 $\mathrm{m} M$, about $11.5 \mathrm{~g} / \mathrm{L})$ used in the culture of maize[20]. This problem remains to be investigated.

\section{ACKNOWLEDGEMENT}

We are grateful to Mr. Chen Nai-xian for his help in photography and to Mrs Fang Jian-ying for her help in the determination of amino acids.

\section{REFERENCES}

[1] Chouard P, Aghion D. Modalites de la formation de bourgeons floraux sur des cultures de segments de tige de tabac. C R Acad Sci (Paris) 1961; 252:3864-6.

[2] Scorza R. in vitro flowering. Hort Rev 1982; 4:106-27.

[3] Wardell WL, Skoog F. Flower formation in excised tobacco stem segments. III Deoxyribonucleic acid content in stem tissue of vegetative and flowering tobacco plants. Plant Physiology 1973; 52:215-20.

[4] Lozhnikova VN, Machackova I, Eder J, Krekule J, Chailakhyan MCh. Gradient of free IAA level in the day-neutral tobacco var, Trapezond with normal and reversed gradient of flowering. Plant Physiol Biochem 1989; 27:127-9.

[5] Negertsky VA, Lozhnikova VN, Chailakhyan MCh. Changes in the activity of phytohormones in reversing the flowering gradient in day-neutral tobacco var Trapezond. Fiziol Rast 1984; 31:1133-48.

[6] Chailakhyan MCh, Chazhakhyan KhK. On disturbing the physiological flowering gradient in day-neutral plants by means of stem girdling and biologically active substances. Dokl Akad 
Nauk SSSR 1975; 217:729-36.

[7] Tiburcio AF, Kaur-Sawhney R, Calston AW. Polyamine biosynthesis during vegetative and floral bud differentiation in thin layer tobacco tissue cultures. Plant Cell Physiol 1988; 29:1241-9.

[8] Kaur-Sawhney R, Tiburcio AF, Galston AW. Spermidine and flower bud differentiation in thinlayer tobacco tissue cultuers. Planta 1988; 173:282-4.

[9] Vallee JC, Perdrizet E, Vansuyt G. Gradient d induction florable et equilibre en acides amines libres dans la tige du Nicotiana Xanthi n.c influence des temperatures supra-optimales. C R Acad Sci Paris Serie D 1969; 269:1190-3.

[10] Bernier G, Kinet JM, Sachs RM. The physiology of flowering. Vol II CRC Press Inc 1981:126.

[11] Chen YN, Li WA. Origin of floral buds in tobacco pedicels cultured in vitro. Acta Botanical Boreali-Occidentalia Sinica. 1992; 12(3):199-203.

[12] Murashige T, Skoog F. A revised medium for rapid growth and bioassays with tobacco tissue cultures. Physiol Plant 1962; 15:473-97.

[13] Chen YN, Li WA. De novo flower bud differentiation in tissue culture of Marigold, Violet orychophragmus and tobacco. Chin. Sci. Bull. 1993; 38(3):235-8.

[14] Wang J J, Fang JY. Effects of various extraction media on the determination of free amino acid. Plant Physiol Communications 1987; 4:50-3.

[15] Sachs T. Pattern formation in plant tissues. Cambridge University Press 1991;186.

[16] Tanimoto S, Miyazaki A, Harada H. Regulation by abscisic acid of in vitro flower formation in Torenia stem segments. Plant Cell Physiol 1985; 26:675-82.

[17] Kutacek M. Enzymes of auxin synthesis in plants and tissue cultures. In: Physiology and biochemistry of auxins in plants (Kutacek M, Bandurski RS, Krekule J. eds.), Academia Praha 1998:57-64.

[18] Bernier G. The control of floral evocation and morphogenesis. Ann Rev Plant Physiol Plant Mol Biol 1988; 39:175-219.

[19] Tang ZC. Accumulation of proline in stressed plants and its possible significance. Plant Physiol Communications 1984;1:15-21.

[20] Armstrong CL, Green CE. Establishment and maintenance of friable, embryogenic maize callus and the involvement of L-proline. Planta 1985; 164:207-14.

Received 16-11-1991. Revised 27-7-1992. Accepted 4-9-1992.

Fig 1. Floral buds without any leaves directly regenerated from Thin Cell Layers (TCLs) of pedicel, about X 6

Fig 2. Flower formation from pedicel segments were inhibited with the concentration of L-Pro increasing (from left to right, L-Pro: $10,100,1000 \mathrm{mg} / \mathrm{L}$ ). X 0.6

Fig 3. Any combination of 6-B A with L-Trp promoted flower bud formation from pedicel segments. But, single 6-BA or L-Trp (except for 6-BA $0.4 \mathrm{mg} / \mathrm{L}$ few segments regenerated few floral buds on this medium), no floral bud neoformation had been observed. $\mathrm{X} 0.5$

Fig 4. Floral buds neoformation from pedicel segments cultured on the basic medium plus 6-BA $2 \mathrm{mg} / \mathrm{L}$ and L-Trp $4 \mathrm{mg} / \mathrm{L}$ for $24 \mathrm{~d}$. X 1.1

Fig 5. Vegetative buds differentiated from stem TCLs cultured on the basic medium plus 6-BA $0.4 \mathrm{mg} / \mathrm{L}$ and L-Trp $32 \mathrm{mg} / \mathrm{L}$ for $22 \mathrm{~d}$. X 1.1

Fig 6. Influence of different concentrations of L-Pro on vegetative bud differentiation of leaf pieces [the medium: the basic medium + IAA $2 \mathrm{mg} / \mathrm{L}+6-\mathrm{B} \mathrm{A} 0.2 \mathrm{mg} / \mathrm{L}$ + L-Pro 0, 10,100 , or $1000 \mathrm{mg} / \mathrm{L}$ (from left to right)]. X 0.5 
Florl gradient and free amino acids in flowering tobacco

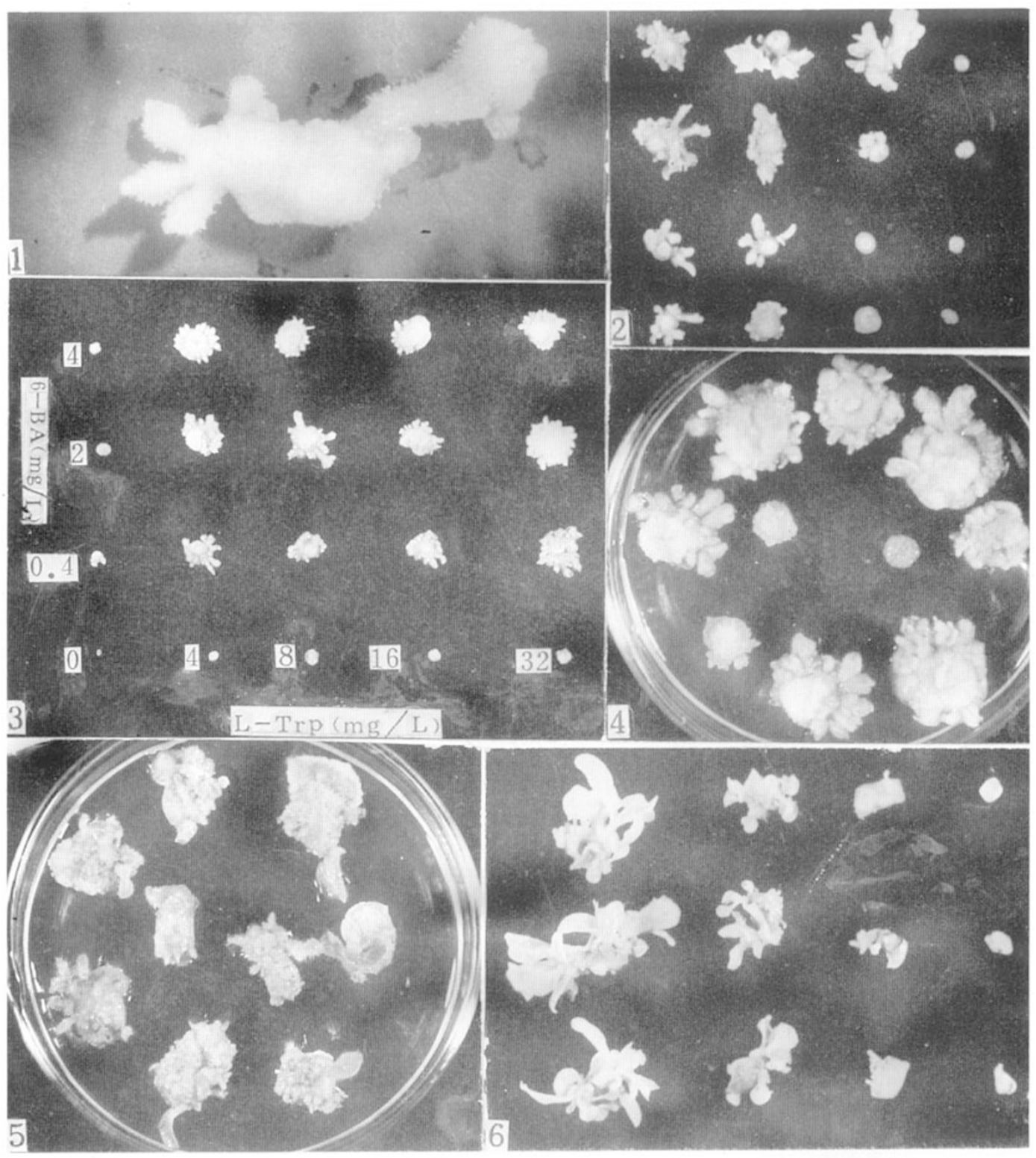

